\title{
Deflection Test Results on D0 RunIIb Stave
}

\author{
Giobatta Lanfranco \\ Fermi National Accelerator Laboratory \\ Particle Physics Division / Silicon Engineering Group - Mechanical Dep. \\ e-mail:giobatta@fnal.gov
}

9 September 2003

\section{Abstract}

The D0 RunIIb final design stave has been tested to verify its actual mechanical performance. The effectiveness of four G-11 (fiberglass/epoxy) braces to bridge the two channels has been investigated as well. All staves have met the goal stiffness for the silicon area. The stave mockups with braces have shown excellent stiffness in complete agreement with what theoretically calculated.

\section{Deflection test}

\subsection{Test description}

Four sapphire bearings glued on carbon fiber plates simulate the stave bulkhead supports. These plates are mounted on two aluminum blocks interconnected by two 1" OD rods. The whole supporting structure is glued onto the CMM granite table. Figure 1 illustrates the test setup.

Two different mechanical staves were investigated. Mechanical Stave \#1 was initially tested without braces $^{1}$. That test indicated that some local deflection and rotation of the C-channels was occurring. A set of carbon fiber braces was installed at the mid-span of the C-channels to eliminate this unwanted motion. Mechanical stave \#3 was tested after complete assembly with G-11 braces. The G-11 material was preferred over carbon fiber for electrical reasons (an enclosed conductive tube would act as a

\footnotetext{
${ }^{1}$ Small strips used to interconnect the upper and lower flanges of the channels, also called bridges.
} 
transformer to transfer noise to the silicon enclosed within it). G-11 performs similarly to G-10/FR4 (Table 2 G-11 reports its properties) and has the advantage that it does not contain any flame retardant ${ }^{2}$. Four brass pieces with masses of 144.0 - $144.4 \mathrm{gr}$ were used for the load test. The load was applied at the mid-span on the stave, directly on the silicon for mechanical stave \#1 with carbon fiber bridges, but on top of channel flanges in the other two cases. The load test steps are summarized in Table 1. The purpose of step 2 was to have the stave well settled in the supporting bearing. The stave was unloaded and measured before applying any subsequent load with the intention to find out whether the structure behaved elastically or not and to investigate if there was a shear component to the deflection.

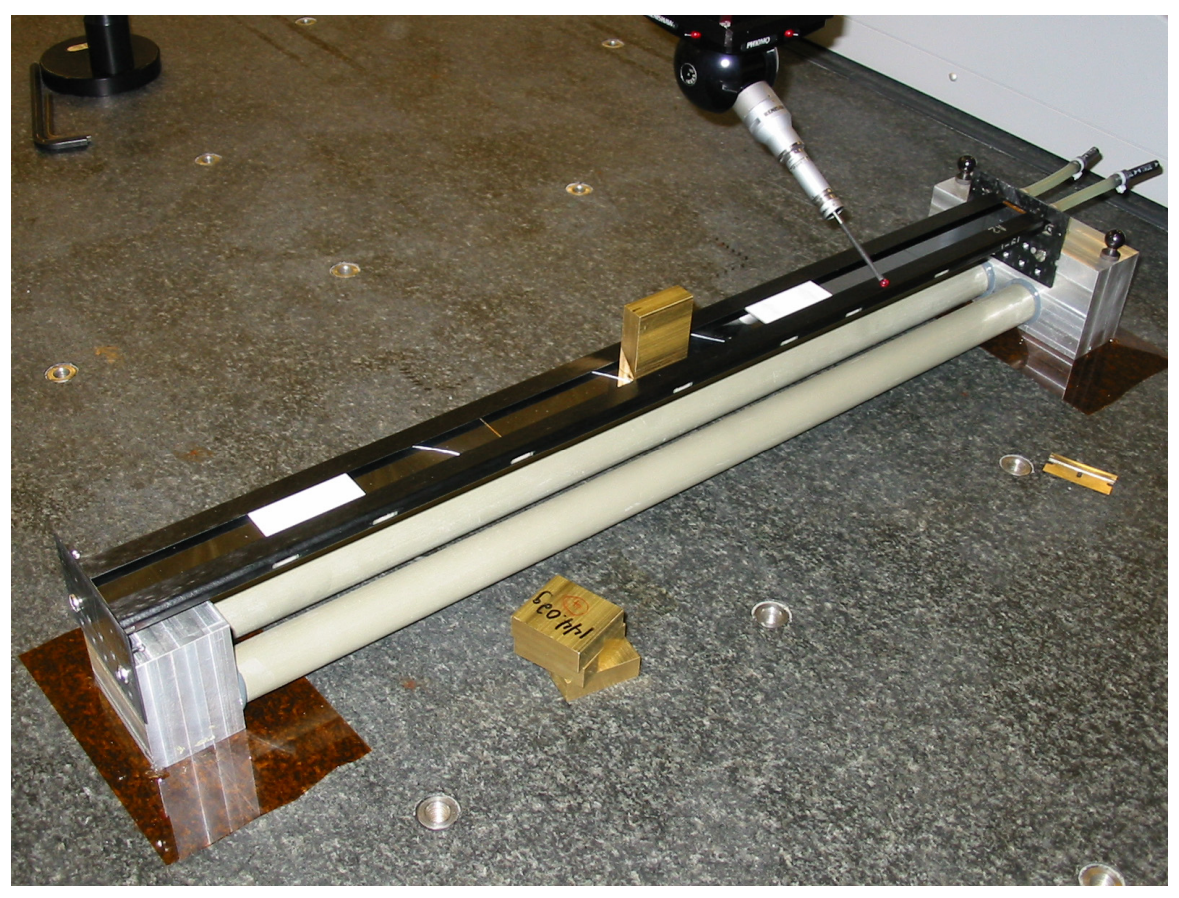

Figure 1 - The deflection test setup.

\footnotetext{
${ }^{2}$ Flame retardants have two disadvantages: they contain heavy elements that lower the radiation length of the material and contain ions which, once liberated under irradiation, may migrate into the silicon damaging it or attack the aluminum wire bonds connecting the electronics to the sensors.
} 


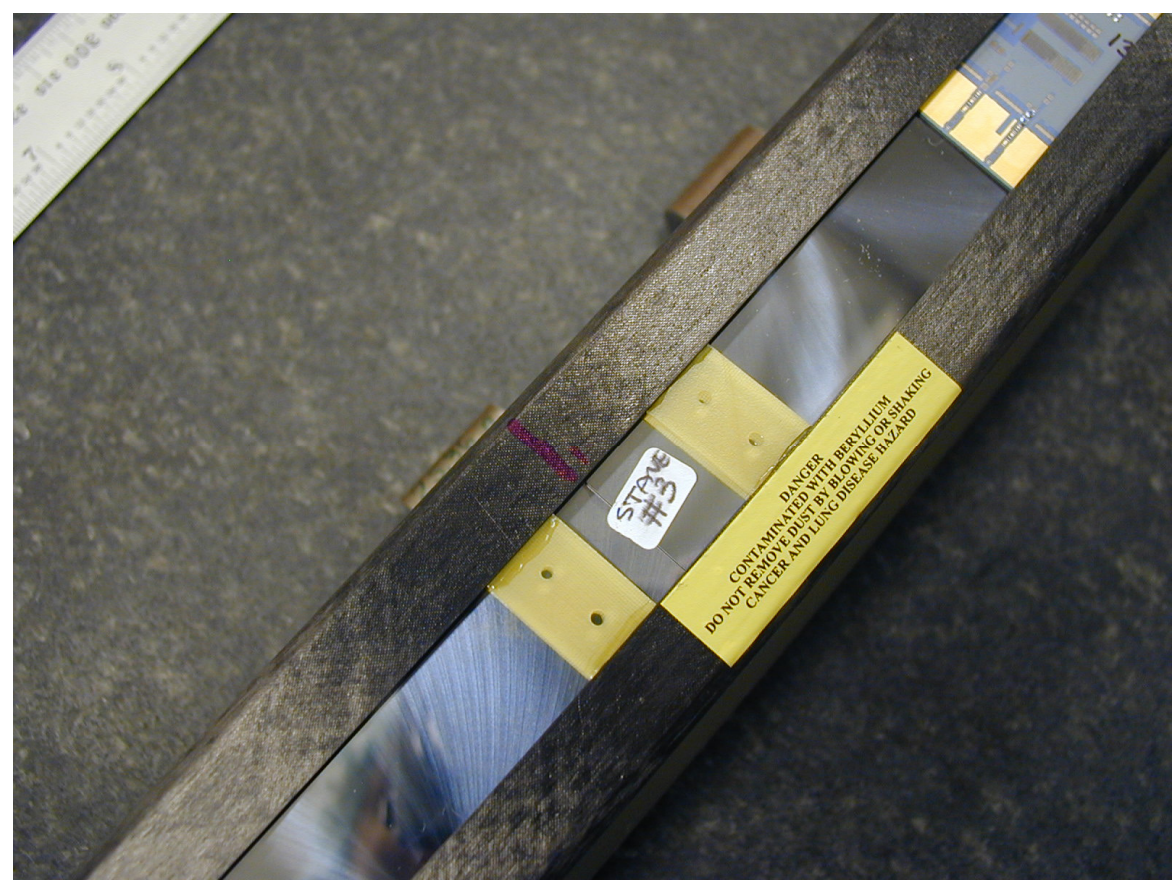

Figure 2 - Detail of the G11 bridges on mechanical stave \#3.

\begin{tabular}{|c|c|c|}
\hline STEP & Load Condition & $\begin{array}{c}\text { Concentrated } \\
\text { mass [grams] }\end{array}$ \\
\hline 1 & No load & - \\
\hline 2 & $3 \mathrm{M}$ & 433.1 \\
\hline 3 & No load & - \\
\hline 4 & $2 \mathrm{M}$ & 288.8 \\
\hline 5 & No load & - \\
\hline 6 & $3 \mathrm{M}$ & 433.1 \\
\hline 7 & No load & - \\
\hline 8 & $4 \mathrm{M}$ & 577.1 \\
\hline 9 & No load & - \\
\hline
\end{tabular}

Table 1 - Deflection test load steps

A total of 11 points were measured at each stave section, with 34 sections taken along the $600 \mathrm{~mm}$ length of the stave. In Figure 3 the points are sketched with the same symbols used in the charts of Figure 4 through Figure 6. Green and red colors are used for left and right channels, respectively, while blue points are measurements taken on the silicon surface. 


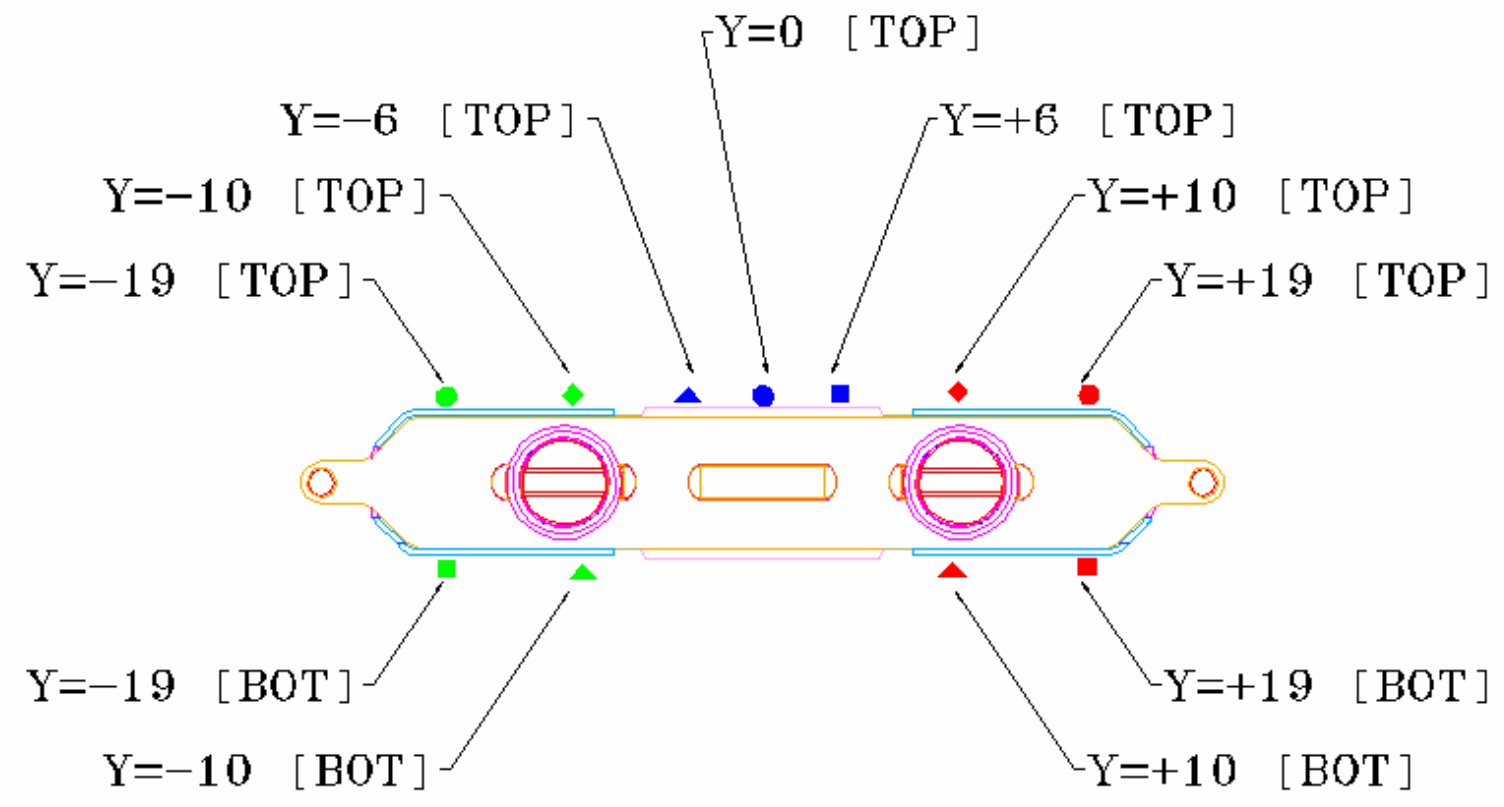

Figure 3-A total of 11 points has been measured at each stave section. The same shape and color of the points appear on each charts (for clarity this illustration has been anyway reported on each graph). Green and red colors are used for left and right channels respectively, blue for the sensors. Points at similar locations have similar shape.

\subsection{Deflection test results}

The target bending stiffness of the RunIIb stave is $69.9 \mathrm{~N} \times \mathrm{m}^{2}$, equivalent to a sag of $60 \mu \mathrm{m}$ under its own mass and the mass of electrical cables and coolant. The projected deflection of such a stave in the various loading conditions is drawn in Figure 4 through Figure 6 with a green solid line.

Based on the channel carbon fiber laminate properties and the stave geometry, a theoretical estimate of the bending performance of the effective stave has been calculated as well and found equal to 91.96 $\mathrm{N} \times \mathrm{m}^{2}$. In Figure 4 through Figure 6 the black dotted line represents the strain the real stave is expected to undergo.

In Figure 4 the deflections of the mechanical stave \#1 without bridges are charted. Despite the non uniform channel behaviour, the measured bending stiffness on the silicon area is $69.1 \mathrm{~N} \times \mathrm{m}^{2}$, comparable with the target stiffness; this translates in a maximum deflection of the sensor area of $60.5 \mu \mathrm{m}$ for the case of stave simply supported under its own weight (145gr).

The two bridged mockups performed in excellent agreement with what theoretically estimated. As expected, the braces effectively carry the shear stresses between the two channels reducing the torque on the channels in the mid span region. This greatly reduces the flange rotation and induces a more homogeneous behaviour of the whole structure as it can be seen in Figure 5. The dramatic 
improvement of the mechanical stave \#1 performance once that the carbon fiber bridges were glued on is clearly visible. All points deflected in a more consistent way and the measured bending stiffness of the whole stave turned out to be $83.9 \mathrm{~N} \times \mathrm{m}^{2}$ (a $21 \%$ increase, i.e. 49.8 micron sag for the case of stave simply supported under its own weight).

Since the two channels must be electrically insulated from each other, glass epoxy G-11 bridges were tested. Deflection results for load condition $4 \mathrm{M}$ are depicted in Figure 6 . The slightly higher bending stiffness of mechanical stave \#3 (87.49 $\mathrm{N} \times \mathrm{m}^{2}$ versus $83.9 \mathrm{~N} \times \mathrm{m}^{2}$ of stave \#1 with carbon fiber braces) proved that switching the bridges material to G-11 did not compromise the stave performance.

The points measured on the silicon surface under the load condition $3 \mathrm{M}$ for the three mockups have been averaged and plotted in Figure 7 confirming what said so far.

Finally, it can be seen in Figure 8 that before and after the loading test (step 1 and step 9 respectively) the sensor profile did not retain any significant memory of the load test confirming the good elastic performance of the stave.

In $\S 4$ (Appendix - Theoretical Deflection Calculations) it is possible to find the calculations relative to what theoretically predicted. 
STAVE DEFLECTION - MECH STAVE \#1 wo/ BRIDGES

$3 \mathrm{M}$

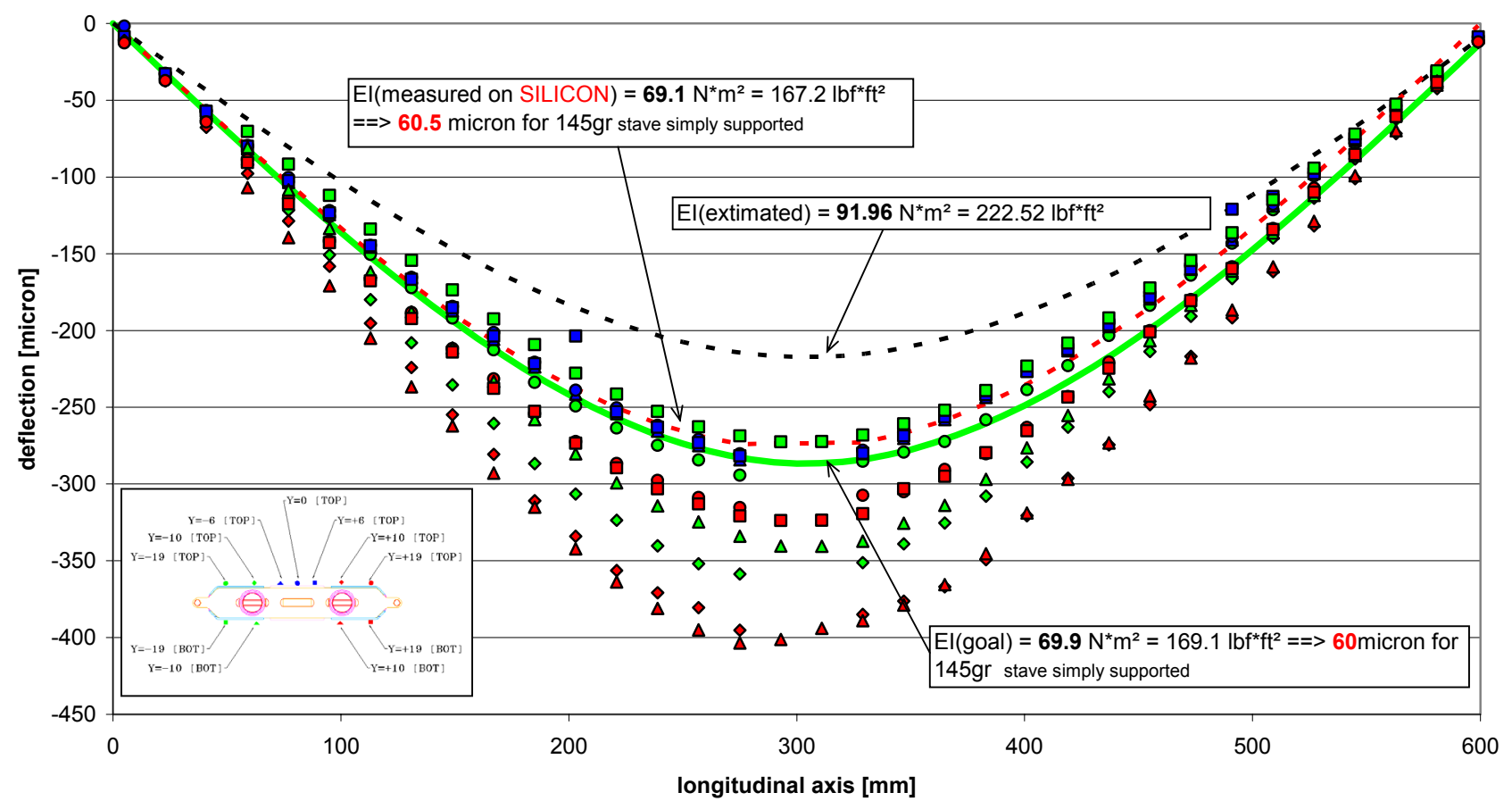

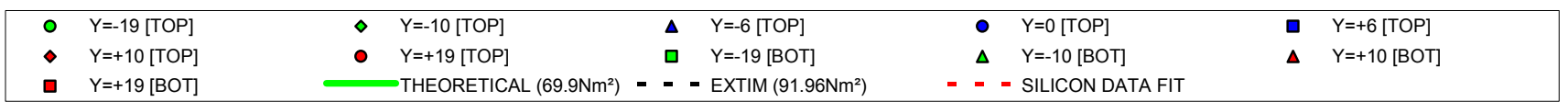

Figure 4 - Load condition 3M on mechanical stave \#1 without bridges. While the silicon sensor surface deflects in a homogeneous way, the channel flanges rotate considerably due to the fact that the absence of a structure bridging the shear stresses from one channel to the other induces a torque on the channel itself. Despite the non uniform channel behaviour, the measured bending stiffness on the silicon area is $69.1 \mathrm{~N} \times \mathrm{m}^{2}$, comparable with the target stiffness; this translates in a maximum deflection of the sensor area of 60.5 micron for the case of stave simply supported under its own weight (145gr).

${ }^{3}$ The center of torsion of a $\mathrm{C}$ shaped section is located outside of the part, i.e. - respect to the web - opposite to its center of mass. 
STAVE DEFLECTION - MECH STAVE \#1 w/ CF BRIDGES

$4 \mathrm{M}$

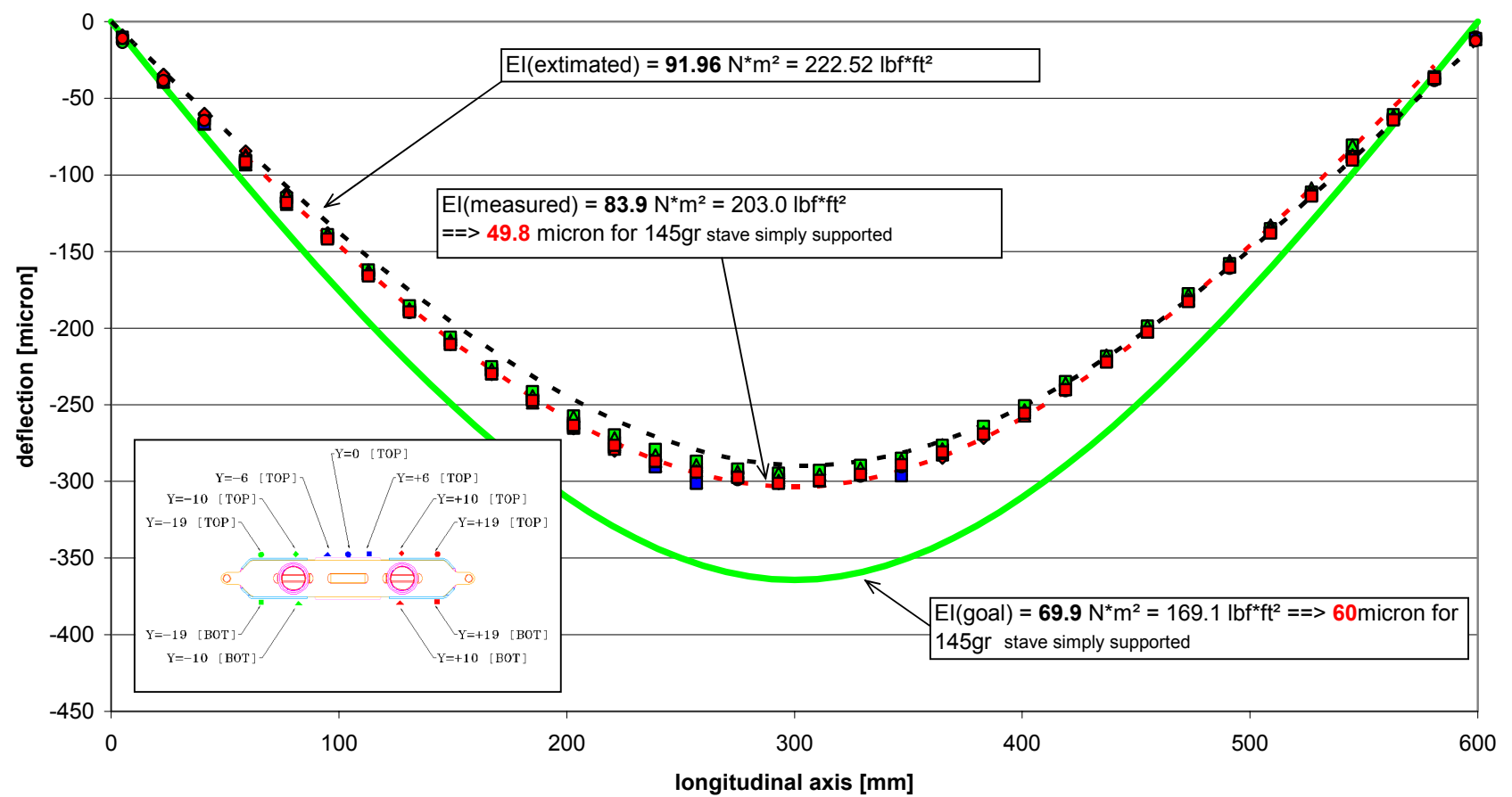

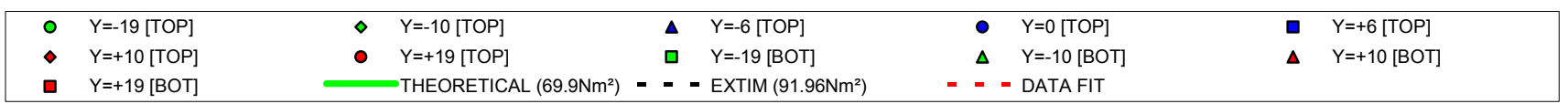

Figure 5 - Load condition 4M on mechanical stave \#1 with carbon fiber bridges. The measured bending stiffness of the stave is $83.9 \mathrm{~N} \times \mathrm{m}^{2}$ which translates in a maximum deflection of 49.8 micron for the case of stave simply supported under its own weight (145gr). 
STAVE DEFLECTION - MECH STAVE \#3 w/ G-11 BRIDGES

$4 \mathrm{M}$

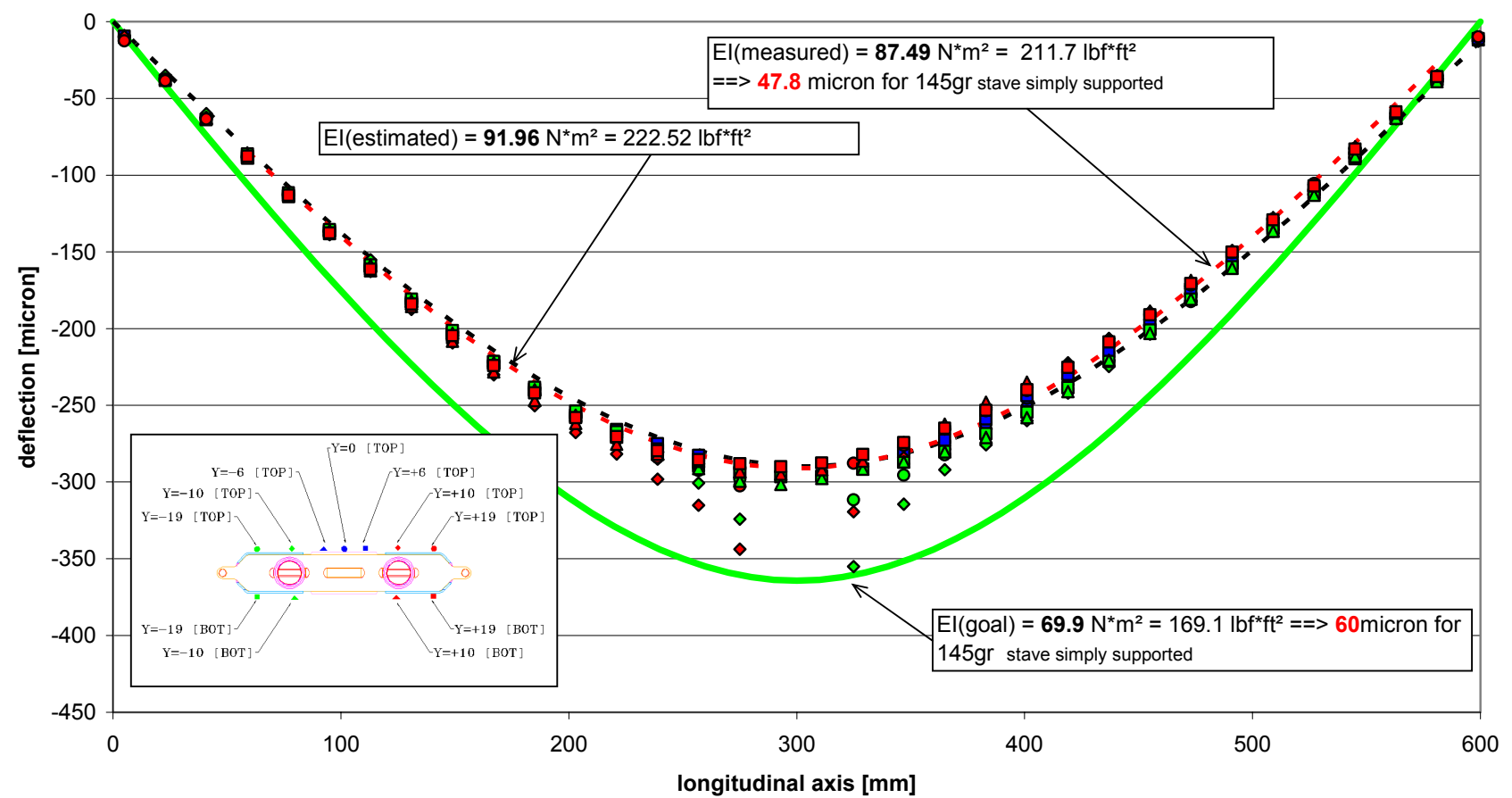

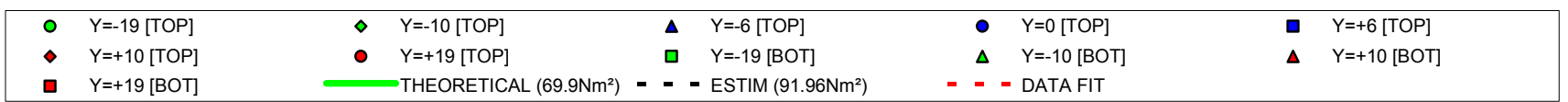

Figure 6 - Load condition 4M on mechanical stave \#3 with G11 bridges. The measured bending stiffness of the stave is $87.49 \mathrm{~N} \times \mathrm{m}^{2}$ which translates in a maximum deflection of 47.8 micron for the case of stave simply supported under its own weight (145gr). 


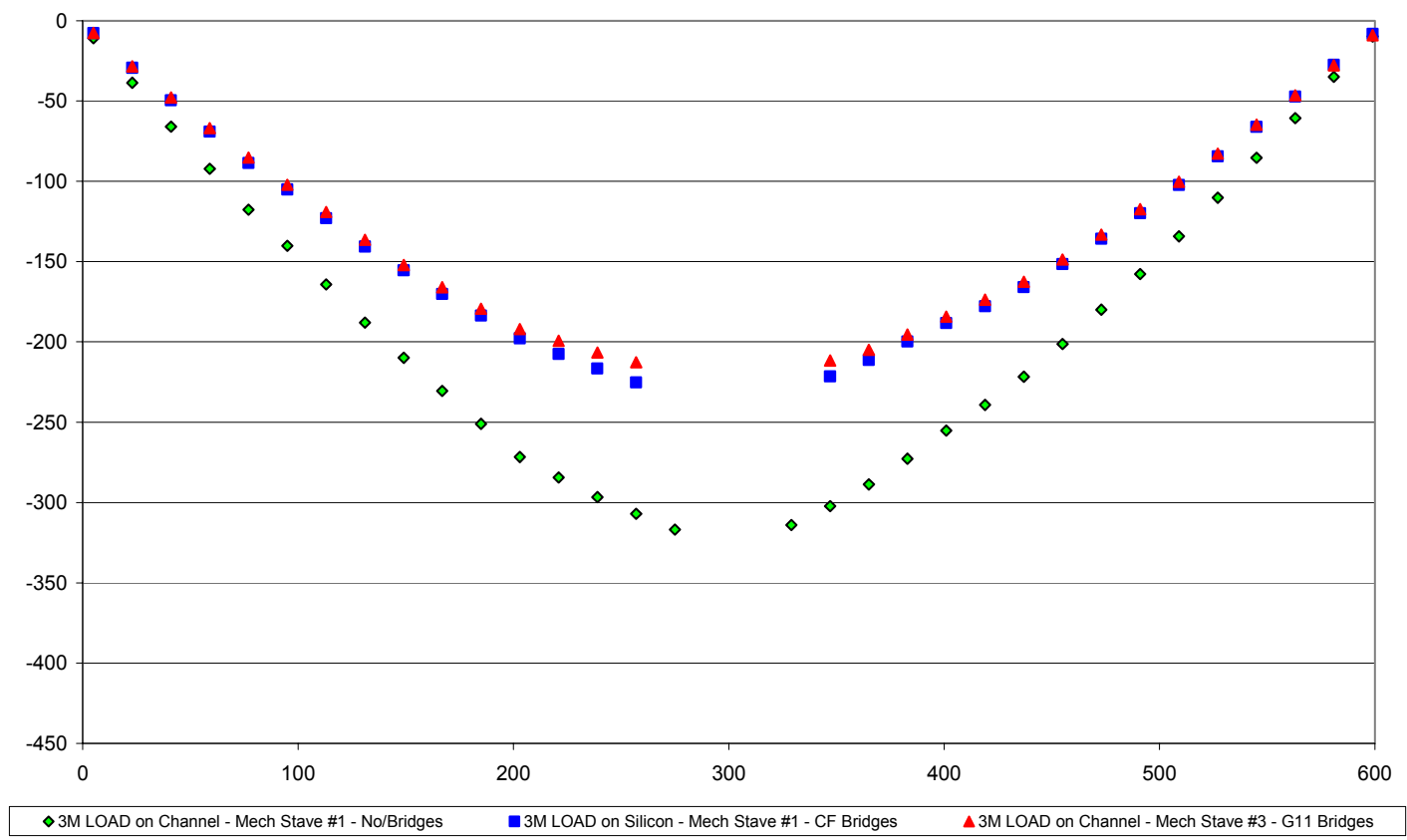

Figure 7 - Effect of channel bridging on stave deflection performance. The averaged data points measured on top of the silicon surface are charted for three different stave mockups: mechanical stave \# 1 with and without carbon fiber bridges connecting the two channels and mechanical stave \#3 with G11 bridges. The carbon fiber and the G11 bridges show similar performance, clearly superior to the bridgeless solution given this latter is unable to effectively carry the shear stresses between the two channels. The load on the mechanical stave \#1 with carbon fiber bridges has been placed on the silicon surface; in the other two cases directly on the channels.

\begin{tabular}{|l|c|}
\hline \multicolumn{1}{|c|}{ SPEC } & $\begin{array}{c}\text { GLASS EPOXY } \\
\text { G-11 }\end{array}$ \\
\hline Specific Gravity & 1.82 \\
\hline Tensile Strength (psi) & 37,000 \\
\hline Comp. Strength (psi) & 63,000 \\
\hline Flexural Strength (psi) & 75,000 \\
\hline Hardness, M Scale & 112 \\
\hline Bond Strength (lbs) & 2200 \\
\hline Shear Strength (lbs) & 22,000 \\
\hline Dissipation Factor $10^{6}$ Cycles, Cond.A & .020 \\
\hline Dielectric Constant $10^{6}$ Cycles, Cond.A & 5.0 \\
\hline Electric Strength V/Mil Cond.A & 900 \\
\hline Flammability Rating & $94 \mathrm{HB}$ \\
\hline Max Oper. Temp ${ }^{\circ} \mathrm{C}$ & 180 \\
\hline Coeff. Thermal Exp. in $/$ in $/{ }^{\circ} \mathrm{C} \mathrm{X} 10^{-5}$ & 1.1 \\
\hline Water Absorbtion $\%$ - 24 Hrs & .20 \\
\hline Military/Fed Spec & Mil-I-24768/3 \\
\hline
\end{tabular}

Table 2 - Glass Epoxy G-11 properties. 

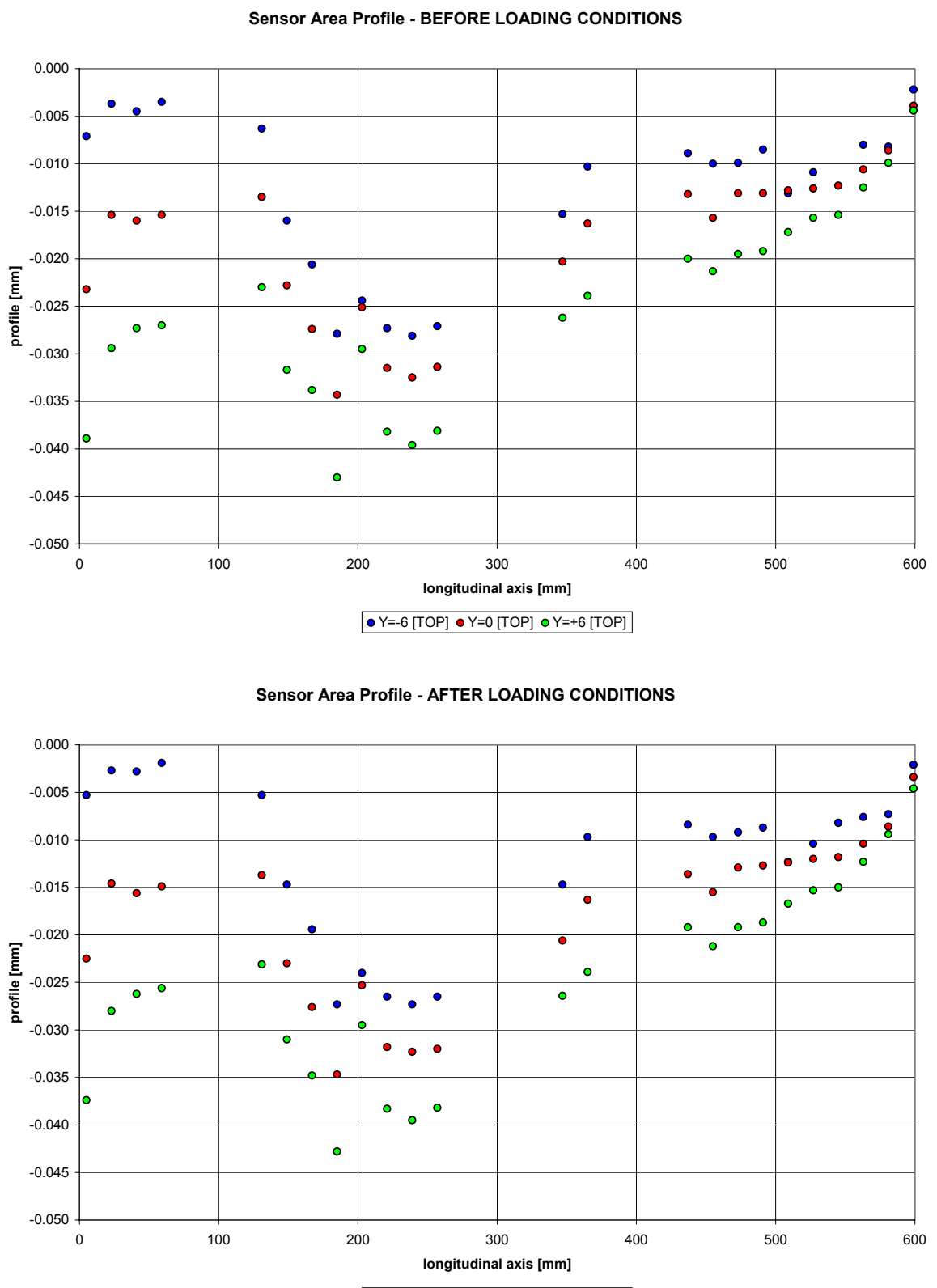

$\bullet Y=-6[T O P] \bullet Y=0[T O P] \circ Y=+6[T O P]$

Figure 8-Longitudinal sensor profile. Each sensor is contained within the vertical grid lines. The good elastic performance of the stave can be seen in the similar sensor profile before and after the loading condition.

\section{Summary}

The D0 RunIIb final design stave was successfully tested and the measured mechanical performance proved to be in great agreement with what theoretically predicted. The epoxy glass G-11 braces confirmed to be effective in minimizing the channel rotation and allowed the stave achieve and exceed the required stiffness. 


\section{Appendix - Theoretical Deflection Calculations}

\section{STAVE DEFLECTION}

This code calculates the goal EI for the stave assuming the sag for $0.0131 \mathrm{bf} / \mathrm{in}$ is 60 micron and then compares this goal EI with the actual one and gives an estimate of the sag such actual stave would have under $0.013 \mathrm{lbf} / \mathrm{in}$

micron : $=0.001 \mathrm{~mm}$

mils $:=\frac{1}{1000} \cdot$ in

channel wall thickness

$t:=400$ micron

9 plies lay-up $0 \pm 45000 \pm 450$

K1392U / BT250E-1

t_laminate $=400$ microns $==>29.3 \%$ resin content by mass

$E:=2.415 \times 10^{11} \cdot \mathrm{Pa}$

stave length

$L:=24 \cdot$ in

web height (see page 279 notebook 1)

$h h:=2.5 \mathrm{~mm}$

distance between mid line flanges

$H H:=8 m m+t$

flange width

$w:=14.5 \mathrm{~mm}$

channel section angle

$\alpha:=47.5 \cdot \frac{\pi}{180}$

$w w:=w-\frac{(H H-h h)}{2 \tan (\alpha)}-\frac{t}{2}$

$w w=11.597 \mathrm{~mm}$

expected stave distributed load

$p:=145 \cdot g \frac{g m}{L}$

maximum allowed sag 
$y_{\text {allowed }}:=60$ micron

target bending stiffness

$$
\begin{aligned}
& E I_{\text {ref }}:=\frac{5}{384} \cdot \frac{p \cdot L^{4}}{y_{\text {allowed }}} \\
& E I_{\text {ref }}=69.905 \mathrm{~m}^{4} \mathrm{~Pa}
\end{aligned}
$$

Section moment of inertia

$$
\begin{aligned}
& I:=2 \cdot\left[\frac{1}{12} \cdot t \cdot h h^{3}+2 \cdot\left(\frac{1}{12} \cdot w w \cdot t^{3}+w w \cdot t \cdot \frac{H H^{2}}{4}\right)+2 \cdot \int_{0}^{\frac{H H-h h}{2 \cdot \sin (\alpha)}}\left(\frac{h h}{2}+I \cdot \sin (\alpha)\right)^{2} \cdot t d l\right] \\
& I=380.779 \mathrm{~mm}^{4}
\end{aligned}
$$

Effective bending stiffness

$$
E \cdot I=91.958 \mathrm{~m}^{4} \mathrm{~Pa}
$$

percentage bending stiffness increment

$$
\begin{aligned}
& \text { El_rate }:=\frac{E \cdot I}{E I_{\text {ref }}} \\
& \text { El_rate }=131.546 \%
\end{aligned}
$$

expected sag for $0.0131 \mathrm{bf} /$ in and simply supported beam

$$
\begin{aligned}
& \text { sag }_{\text {exptd }}:=\frac{5}{384} \cdot \frac{p \cdot L^{4}}{E \cdot l} \\
& \text { sag }_{\text {exptd }}=45.61 \text { micron }
\end{aligned}
$$

fundamental frequency (formula for elliptical plate)

$$
\begin{aligned}
& K_{n}:=9.87 \\
& f_{n}:=\frac{K_{n}}{2 \cdot \pi} \cdot \sqrt{\frac{E \cdot I \cdot g}{p \cdot L^{4}}} \\
& f_{n}=83.1 \mathrm{~Hz}
\end{aligned}
$$

\section{Further Considerations - deflection test}

Brass masses and consequent loads

$$
\begin{aligned}
& \text { Mbrass } 1:=144.39 \mathrm{gm} \\
& \text { Mbrass } 2:=144.38 \mathrm{gm} \\
& \text { Mbrass } 3:=144.32 \mathrm{gm} \\
& \text { Mbrass4 }:=144.02 \mathrm{gm}
\end{aligned}
$$




$$
\begin{aligned}
& \operatorname{LOAD}_{1}:=\text { Mbrass }_{1} \\
& \operatorname{LOAD}_{2}:=\sum_{i=1}^{2} \text { Mbrass }_{i} \\
& \mathrm{LOAD}_{3}:=\sum_{i=1}^{3} \text { Mbrass }_{i} \\
& \operatorname{LOAD}_{4}:=\sum \text { Mbrass }
\end{aligned}
$$$$
L O A D=\left(\begin{array}{c}
0 \\
144.39 \\
288.77 \\
433.09 \\
577.11
\end{array}\right) g m
$$

Deflection of beam left end

$y_{A}:=0 m$

distance from beam left end of concentrated load

$$
a:=\frac{L}{2}
$$

beam section angles for simply supported beam of target stiffness

$$
\theta_{A}(i):=\frac{-L O A D_{i} \cdot g \cdot a}{6 E I_{r e f} \cdot L} \cdot(2 \cdot L-a) \cdot(L-a)
$$

Moment at beam left end

$$
M_{A}:=0 N \cdot m
$$

Reaction force at beam left end

$$
R_{A}(i):=\frac{g L O A D_{i}}{L} \cdot(L-a)
$$

Deflections due to concentrated loading LOADn for simply supported beam of target stiffness and graphical representation

$$
y_{\text {concentrated }}(x, n):=\mid \begin{aligned}
& y_{A}+\theta_{A}(n) \cdot x+\frac{M_{A} \cdot x^{2}}{2 \cdot E I_{\text {ref }}}+\frac{R_{A}(n) \cdot x^{3}}{6 \cdot E I_{\text {ref }}}-\frac{g \cdot L O A D_{n}}{6 \cdot E I_{\text {ref }}} \cdot(x-a)^{3} \text { if }(x \geq a) \\
& y_{A}+\theta_{A}(n) \cdot x+\frac{M_{A} \cdot x^{2}}{2 \cdot E I_{\text {ref }}}+\frac{R_{A}(n) \cdot x^{3}}{6 \cdot E I_{\text {ref }}} \text { otherwise }
\end{aligned}
$$

$x:=0 \mathrm{~mm}, 1 \mathrm{~mm} . .600 \mathrm{~mm}$ 


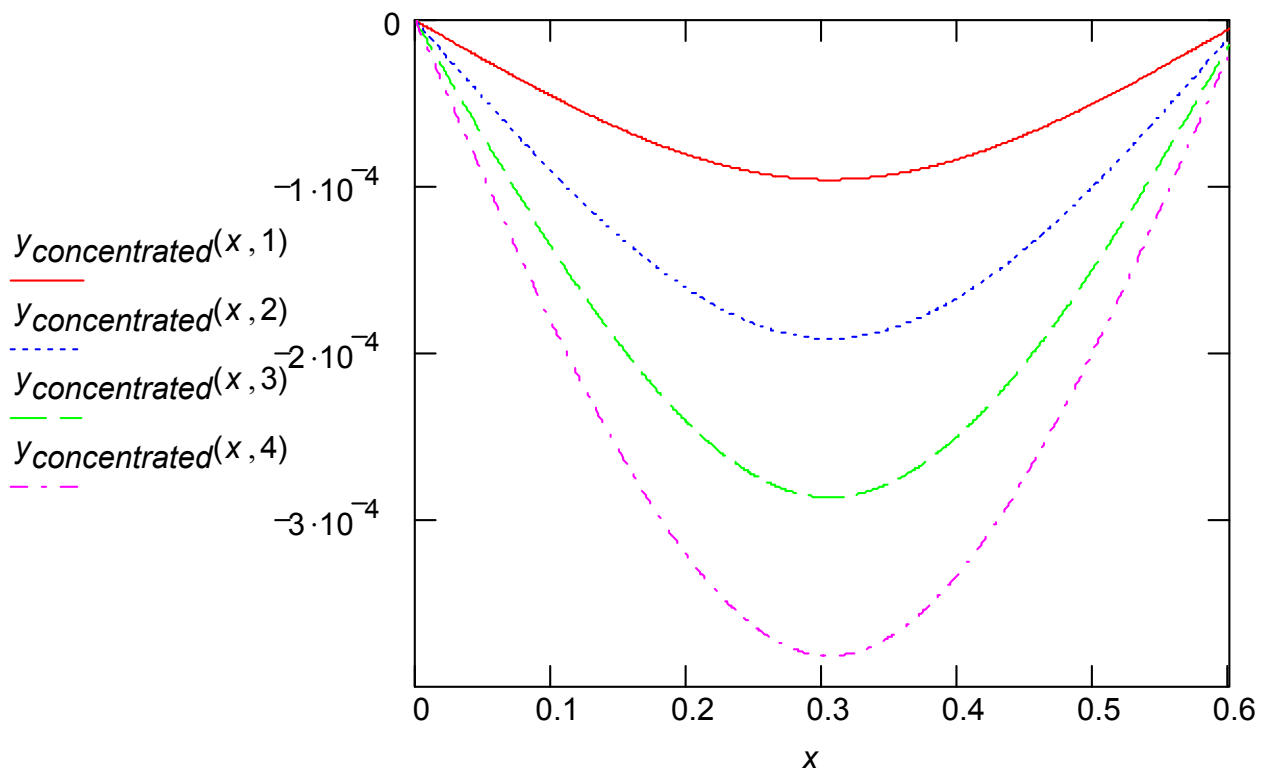

Simply supported target stiffness beam sag for concentrated LOADn

$X:=0 \mathrm{~mm}, 10 \mathrm{~mm} . .600 \cdot \mathrm{mm}$

$n:=1 . .4$

theretical_sag $n:=\frac{1}{48} \cdot \frac{L O A D_{n} g \cdot L^{3}}{E I_{\text {ref }}}$

theretical_sag $=\left(\begin{array}{c}0 \\ 95.596 \\ 191.186 \\ 286.735 \\ 382.087\end{array}\right)$ micron

beam section angles for simply supported beam of effective stiffness

$$
\theta_{A \_ \text {eff }}(i):=\frac{-L O A D_{i} \cdot g \cdot a}{6 E \cdot l \cdot L} \cdot(2 \cdot L-a) \cdot(L-a)
$$

Deflections due to concentrated loading LOADn for simply supported beam of effective stiffness

$$
y_{\text {eff }}(x, n):=\left\{\begin{array}{l}
y_{A}+\theta_{A_{-} \text {eff }}(n) \cdot x+\frac{M_{A} \cdot x^{2}}{2 \cdot E \cdot l}+\frac{R_{A}(n) \cdot x^{3}}{6 \cdot E \cdot l}-\frac{g \cdot L O A D_{n}}{6 \cdot E \cdot l} \cdot(x-a)^{3} \text { if }(x \geq a) \\
y_{A}+\theta_{A} \text { eff }(n) \cdot x+\frac{M_{A} \cdot x^{2}}{2 \cdot E \cdot l}+\frac{R_{A}(n) \cdot x^{3}}{6 \cdot E \cdot l} \text { otherwise }
\end{array}\right.
$$

expected sag for $0.013 \mathrm{lbf} /$ in and simply supported beam given the data fitted bending stiffness EI_fit El_fit $:=87.49 m^{4} \cdot P a$ 
expected_sag_data_fit $:=\frac{5}{384} \cdot \frac{p \cdot L^{4}}{E l \_f i t}$

expected_sag data_fit $=47.8$ micron

beam section angles for simply supported beam of data fitted stiffness

$\theta_{A_{-} f i t}(i):=\frac{-L O A D_{i} \cdot g \cdot a}{6 E I \_f i t \cdot L} \cdot(2 \cdot L-a) \cdot(L-a)$

Deflections due to concentrated loading LOADn for simply supported beam of data fitted stiffness

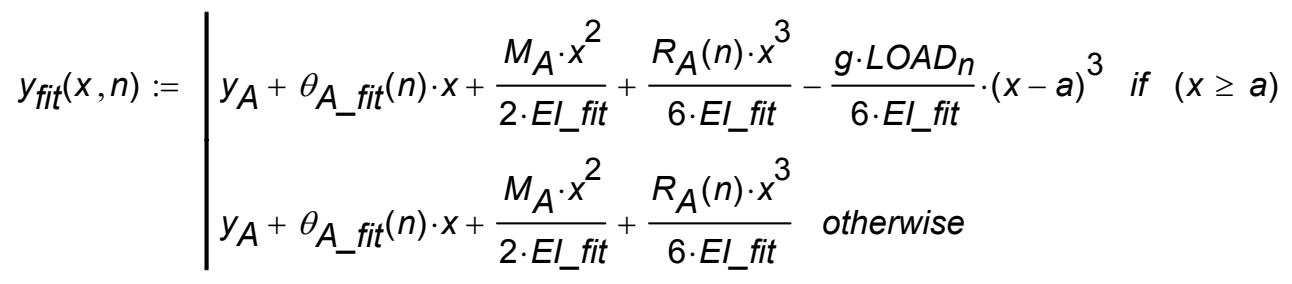

